DOI: http://doi.org/10.21698/simi.2018.ab34

\title{
IMMUNOFLUORESCENCE TECHNIQUE AND SOFTWARE TOOL TO DETECT PHATHOGEN BACTERIA IN DRINKING WATER
}

\author{
Catalina Stoica $^{1}$, Paul-Nicolae Ancuţa ${ }^{2}$, Irina Eugenia Lucaciu ${ }^{1}$, Alina Roxana Banciu ${ }^{1}$, Sorin \\ Sorea $^{2}$, Anca Atanasescu ${ }^{2}$, Mihai Nita-Lazar ${ }^{1}$ \\ ${ }^{1}$ National Research and Development Institute for Industrial Ecology - ECOIND, 71-73 Drumul \\ Podu Dambovitei, district 6, Bucharest, mihai.nita@incdecoind.ro, Romania \\ ${ }^{2}$ National Institute of Research and Development in Mechatronics and Measurement \\ Technique, 6-8 Pantelimon, district 2, Bucharest, ancuta.paul@yahoo.com, Romania
}

Keywords: antibody-antigen interaction, bacteria, drinking water, immunofluorescence, software tool

\section{Introduction}

Monitoring physical-chemical and microbiological parameters of the water quality intended for human consumption should be done according to Council Directive 98/83/EC (supplemented by Commission Directive (EU) 2015/1787) and Romanian legislation (Law no. 458/2002, republished in 2011 and supplemented by Ordinance No.22/2017) requirements. The objective of the Directive is to protect human health from the adverse effects of any contamination of water intended for human consumption by ensuring that it is wholesome and clean. Microbial contamination of drinking water is still a major issue worldwide because it represents a major source of waterborne or water-based illnesses in developing as well as in developed countries and could causes mortality. Numerous methods have been developed for rapid detection and quantification of waterborne pathogenic bacteria, because the traditional methods still are not sufficiently sensitive to detect low concentrations of pathogens considered dangerous in drinking waters.

This paper proposed a new rapid and reliable method to detect the pathogenic bacteria (Escherichia coli and Pseudomonas aeruginosa) by immunofluorescent detection based on the specific interaction between bacteria and tagged fluorochrome antibody followed by image software processing. The digital images delivered by microscopy were automatically processed with a software application that can generate reports in a very short time about presence/absence of analyzed pathogen bacteria in water samples.

\section{Materials and methods}

Bacterial strains used: Pseudomonas aeruginosa (ATCC 27853) and Escherichia coli (ATCC 25922) were purchased from ATCC (USA).

Antibodies: Monoclonal antibody anti-P.aeruginosa tagged with Alexa Fluor 647 and polyclonal antibody anti-E.coli tagged with FITC were purchased from Novus Biologicals (CO, USA).

Specific bacterial detection with fluorescent tagged antibody. Each bacterial strain $\left(0.4 \mathrm{OD}_{600 \mathrm{~nm}}\right)$ was incubated $1 \mathrm{~h}$ at $37^{\circ} \mathrm{C}$ in presence of its specific antibody. The microscopic detection of fluorescent bacteria was performed using Leica DMi8 inverted microscope at a $63 \mathrm{X}$ fold magnification. 


\section{INTERNATIONAL SYMPOSIUM "THE ENVIRONMENT AND THE INDUSTRY", SIMI 2018, BOOK OF ABSTRACTS}

Both brightfield and fluorescence images were processed by a pipeline processing protocol (Figure 1) in order to achieve a fast and specific digital signal linked to the bacterial identification.

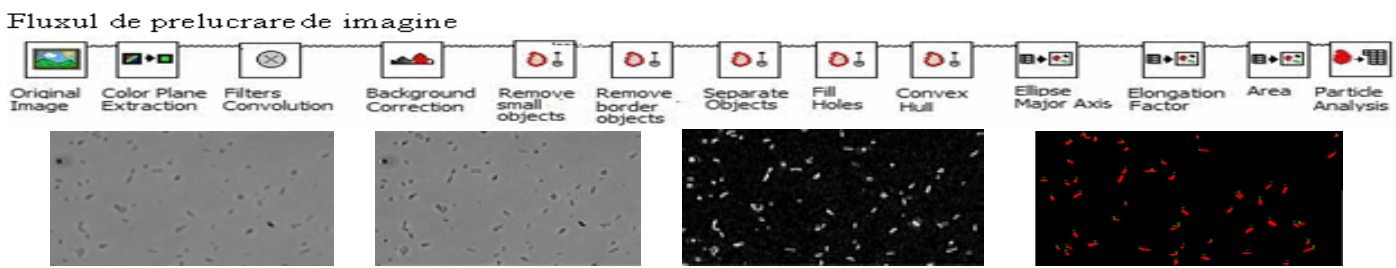

Figure 1. "Pipeline" processing for obtaining image mask and blobs' data analysis

\section{Results and conclusions}

The microscopic images displayed a clear bacterial presence, due to their specific interactions with fluorochome tagged antibody, both in fluorescence and transmitted light (Figures 2 and 3).
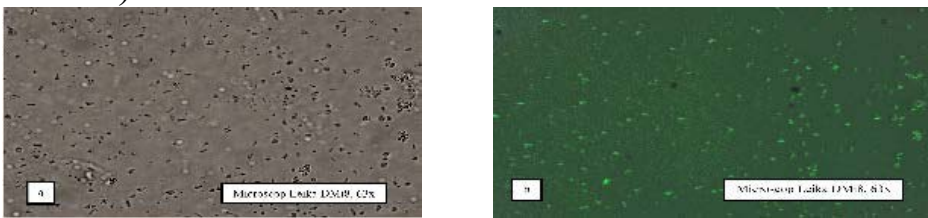

Figure 2. Escherichia coli specific identification (a- brightfield; b- fluorescence)
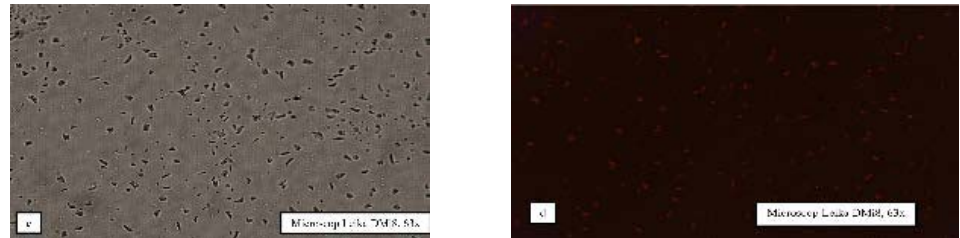

Figure 3. P.aeruginosa specific identification (a- brightfield; b- fluorescence)

The digital images were automatically processed (Figure 1) generating a microbiological reports that contain: the size of the image analyzed in pixels, the presence or absence of the analyzed bacteria, the number of bacteria and colonies detected in the bright image, the number of distinct areas detected in the fluorescence image, the sum of the areas of these areas (in pixels) and the ratio between the sum of the above areas and the size of the image.

Overall, a new detection tool was developed for identification and quantification of pathogenic bacteria from drinking water sample based on the fluorescent image which was analyzed and the results could be sent wireless to all organizations involved in health and environment monitoring.

\section{Acknowledgements}

This paper was supported by a grant of the Romanian National Authority for Scientific Research and Innovation CNCS/CCCDI-UEFISCDI, project number PN-III-P2-2.1-PED-2016-0965 within PNCDI III. 